\title{
ANALISIS KESENJANGAN DAN PERBANDINGAN KAYU PAPI (Exocarpus latifolia R.Br) DENGAN CENDANA (Santalum album Linn.) DI NUSA TENGGARA TIMUR, INDONESIA (Gap Analyses and Comparison of Exocarpus latifolia $R . B r$ with Santalum album Linn. in East Nusa Tenggara, Indonesia)
}

\author{
Aziz Umroni, Heny Rianawati, \& Siswadi \\ Balai Penelitian Kehutanan Kupang, Jl. Alfons Nisnoni (Untung Surapati) No. 7B, Kel. Airnona Kupang, \\ Indonesia; e-mail: aumroni@yahoo.co.id, heny.rianawati@gmail.com, ady_plk@yahoo.com
}

Diterima 8 Oktober 2014, direvisi 30 Desember 2014, disetujui 29 Januari 2015

\begin{abstract}
Shrub sandalwood (Exocarpus latifolia R.Br) is potential for the substitution of sandalwood (Santalum album Linn.) The rising demand and ineffective regulations increase threats toward its sustainability. This research aimed at: 1) conducting gap analyses of information and conservation between sandalwood and shrub sandalwood and 2) comparing production, price and abundance of both species. Analysis 1 used literature review and comparison study while analysis 2 used Importance Value (IV) and comparison. The results showed that: Firstly, there is a significant disparity of information and conservation between both species, i.e there are 319 scientific publications related to sandalwood and four conservation plots have been built, meanwbile only 10 scientific publications about shrub sandahwood and only one conservation plot has been settled; Secondly, the price of shrub sandalwood (IDR $3.15 \mathrm{million} / \mathrm{m}^{3}$ ) is lower than sandahwood (IDR 225 million/ $\mathrm{m}^{3}$ ) and the average production (2009-2012) of shrub sandalwood (700 $\mathrm{m}^{3}$ annually) is higher than sandahwood (166 $\mathrm{m}^{3}$ annually); Thirdly, the abundance of shrub sandalwood in several forests in Timor is lower than sandahwood, i.e IV atpoles and trees of shrub sandalwood are 31-58 and 9-32 respectively, while for sandalwood are 194-234 and 60-209 respectively. The less stands in their habitats and relatively higher wood production indicated that shrub sandahwood is more endangered than sandalwood.
\end{abstract}

Keywords: Gapanalyses, literature review, sandalwood, shrub sandalwood.

\section{ABSTRAK}

Kayu papi (Exocarpus latifolia R.Br) merupakan substitusi cendana (Santalum album Linn.). Peningkatan permintaan dan regulasi yang longgar mengancam kelestariannya. Tujuan penelitian ini adalah: 1) menganalisis kesenjangan informasi dan konservasi kayu papi dan cendana dan 2) membandingkan produksi, harga serta kelimpahan keduanya. Analisis 1 menggunakan metode analisis literatur dan studi perbandingan, sedangkan analisis 2 menggunakan indeks nilai penting (INP) dan metode perbandingan. Hasil penelitian menunjukkan: pertama, kesenjangan informasi dan konservasi kayu papi dan cendana adalah nyata. Terdapat 319 publikasi ilmiah yang memuat informasi tentang cendana dan ada empat plot konservasi cendana. Sementara itu, hanya terdapat 10 publikasi ilmiah tentang kayu papi dan sebuah plot konservasi; kedua, harga kayu papi $\left(\mathrm{Rp} 3,1 \mathrm{juta} / \mathrm{m}^{3}\right)$ lebih rendah dibanding cendana $\left(\mathrm{Rp} 225 \mathrm{juta} / \mathrm{m}^{3}\right)$ dan rataan produksi kayu papi dalam empat tahun terakhir $\left(700 \mathrm{~m}^{3} /\right.$ tahun) lebih tinggi dibanding rataan produksi cendana $\left(166 \mathrm{~m}^{3} /\right.$ tahun); ketiga, kelimpahan kayu papi di beberapa daerah di Timor lebih rendah dibanding cendana. INP kayu papi pada tingkat tiang dan pohon di beberapa kawasan hutan secara berturut-turut adalah 31-57 dan 9-32, sedangkan INP cendana di lahan milik pada tingkat tiang dan pohon adalah 194-234 dan 60-209. Dengan kelimpahan tanaman lebih rendah dan produksi kayu lebih tinggi, kelestarian kayu papi lebih terancam dibanding cendana.

Kata kunci: Analisis kesenjangan, cendana, kayu papi, studi literatur.

\section{PENDAHULUAN}

Kayu papi adalah nama lokal untuk Exocarpus latifolia R.Br yang merupakan suku Santalaceae. Suku Santalaceae pada umumnya menghasilkan wangi yang berasal dari kayunya. Beberapa jenis dari suku
Santalaceae yang terkenal adalah Santalum album Linn. atau east indian sandalwood di Indonesia dan India (Backer, 1965; Chowdury, 1933 dalam Mandang, 1988), Santalum spicatum R.Br. di Australia bagian barat (Talbot, 1983 dalam Mandang, 1988), Santalum freicinetianum Gaud. di 
Hawai (Rock, 1916 dalam Mandang, 1988), Exocarpus latifolia R.Br atau shrub sandalwood di Philiphina, Indonesia, New Guena dan Australia (Oyen \& Huan Dun, 1999) dan Ocyris lanceolata atau african sandalwood di Tanzania (Bhat et al., 2006). Namun dari sekian banyak marga Santalacea, $S$. album yang tumbuh di Nusa Tenggara Timur (NT'T) mempunyai keunggulan komparatif dalam kadar minyak dan produksi kayu teras dibandingkan jenis dari suku Santalaceae lainnya (Dinas Kehutanan dan Perkebunan Kabupaten Timor Tengah Selatan, 2010). Besarnya permintaan cendana tidak diimbangi dengan regenerasinya sehingga saat ini langka dan mahal. Sejak tahun 1990-an kayu papi sering digunakan untuk mencampur cendana. Pasca kelangkaan dan menurunnya produksi kayu teras cendana, permintaan kayu gubal cendana dan kayu papi meningkat tajam dan menjadikan kayu papi sebagai komoditas yang sangat potensial (Sumanto etal., 2011).

Peluang inilah yang dimanfaatkan oleh pelaku pasar untuk substitusi cendana dengan kayu papi. Eksploitasi kayu papi yang kurang terkendali saat ini terjadi karena: 1) banyaknya kemiripan sifat antara kayu papi dengan cendana dari wangi dan penampakan fisiknya, sehingga keduanya substitutif; 2) kelimpahannya di Nusa Tenggara Timur (NTT) yang relatif belum tereksplorasi dan 3) harga perolehan yang jauh lebih murah dari cendana di pemilik langsung. Komparasi dalam suku Santalaceae pernah dilakukan oleh Mandang (1988) yang melakukan komparasi antara S. album dan E. latifolia mengenai aspek anatomi kayu, Bhat et al. (2006) yang mengomparasikan $S$. album dan O. lanceleolata dalam aspek kandungan minyak dan kode genetik atau DNA dan Haffner (1993) yang membandingkan kualitas dan kuantitas kayu teras dari dua spesies dari marga Santalum yakni S. album dan $S$. spicatum yang berasal dari Indonesia dan Australia.

Permasalahan pengelolaan kayu papi lainnya adalah budidayanya memerlukan upaya ekstra karena termasuk jenis semiparasit (hemyparasite) yang memerlukan tanaman inang untuk menopang kehidupannya (Oyen \& Huan Dun, 1999). Sementara itu, kegiatan eksploitasi kayu papi terus berlangsung dengan regulasi yang mengatur peredaran dan konservasinya relatif lebih longgar dibandingkan cendana. Dengan nilai komersial yang jauh lebih rendah tetapi memiliki manfaat yang hampir sama dengan cendana menyebabkan ancaman terhadap kelestarian kayu papi di habitat alaminya meningkat. Tulisan ini bertujuan untuk melakukan studi komparasi antara cendana dan kayu papi dalam aspek produksi, kelimpahan, nilai ekonomi, regulasi, budidaya serta kesenjangan penelitian (research gap) yang bermanfaat untuk menentukan prioritas yang perlu dilakukan.

\section{METODE PENELITIAN}

\section{A. Lokasi dan Waktu Penelitian}

Penelitian mengenai sebaran dan kelimpahan kayu papi dilaksanakan di Pulau Timor, meliputi: Kabupaten Belu, Timor Tengah Utara (T'TU), Timor Tengah Selatan (TTS) dan Kabupaten Kupang. Kegiatan ini dilaksanakan pada tahun 2012. Pengumpulan data sekunder tentang produksi dan studi pustaka (literature review) dilaksanakan pada tahun 2013 sampai dengan 2014.

\section{B. Pengumpulan Data}

Data yang dikumpulkan adalah data primer dan data sekunder. Data primer yang dikumpulkan adalah data kelimpahan (sebaran dan dominansi) kayu papi di NT'T. Data primer dikumpulkan melalui survei lapangan. Data sekunder yang dikumpulkan antara lain: a) aspek anatomi dan morfologi kayu papi dan kayu cendana, b) informasi tentang jumlah publikasi ilmiah, upaya konservasi dan silvikultur kayu papi dan cendana, c) produksi kayu dan peredaran kayu papi dan cendana di NT'T. Data sekunder diperoleh dengan studi pustaka publikasi online dari Google Schoolar dan EBSCO Host (Cires et al., 2013), IUCN Red List dan Dinas Kehutanan Provinsi dan Kabupaten di NTTT.

\section{Analisis Data}

\section{Analisis kesenjangan}

Analisis kesenjangan informasi, konservasi dan regulasi antara kayu papi dan cendana dilakukan dengan membandingkan jumlah publikasi ilmiah, kelengkapan informasi silvikultur, jumlah plot/kebun konservasi dan ketersediaan regulasi kayu papi dan cendana. Kesenjangan informasi dinilai nyata jika jumlah publikasi ilmiah jauh berbeda, kelengkapan informasi silvikultur tidak sama dan jumlah plot/kebun konservasi berbeda nyata. 


\section{Analisis perbandingan}

Analisis perbandingan produksi dan harga antara kayu papi dan cendana dilakukan dalam rangka mengetahui perbedaannya, dengan membandingkan tingkat produksi dan harga keduanya.

\section{Analisis kelimpahan tanaman}

Analisis kelimpahan kayu papi dilaksanakan dengan cara menghitung Indeks Nilai Penting (INP), sampling diambil dengan metode transek dengan petak ukur persegi. Nilai INP diukur dengan rumus berikut (Dumbois et al., 1974; Kurniawan et al., 2013):

$\mathrm{INP}=\mathrm{KR}+\mathrm{FR}+\mathrm{DR}$

\section{Dimana:}

KR adalah kerapatan relatif, FR adalah frekuensi relatif dan DR adalah dominasi relatif.

Sementara itu, kelimpahan cendana diperoleh dari publikasi ilmiah. Kelimpahan kayu papi dan cendana selanjutnya dibandingkan untuk mengetahui perbedaannya.

\section{HASIL DAN PEMBAHASAN}

\section{A. Gambaran Kayu Papi dan Cendana}

\section{Aspek anatomi dan morfologi}

Kayu papi mempunyai banyak kemiripan dengan cendana, bahkan secara mikroskopik keduanya mempunyai banyak sekali persamaan anatomis. Secara fisiologis keduanya dapat dibedakan dari: 1) morfologi daun dan buah dan 2) bentuk batang, seperti terlihat pada Tabel 1 .

Cendana dan kayu papi sangat sulit dibedakan dalam bentuk sortimen atau kayu olahannya karena kayu mengeluarkan senyawa aromatik. Keduanya hanya bisa dibedakan secara anatomis, yaitu pada diameter dan frekuensi pori-pori. Diameter pori cendana lebih kecil daripada kayu papi, besarnya berturut-turut adalah 52 dan 68 mikron. Frekuensi pori cendana lebih banyak dari kayu papi, besarnya berturut-turut adalah 64 dan 29 pori $/ \mathrm{mm}^{2}$. Ilustrasi penanda anatominya adalah kayu papi mempunyai pori yang lebih lebar dengan frekuensi yang lebih sedikit dari cendana, sedangkan pori keduanya sama-sama berbentuk oval, soliter dan tidak ada endapan di dalamnya (Mandang, 1988). Ciri anatomi lainnya (parenkim, jari-jari sel dan serat) relatif identik. Menurut Bhat et al. (2006) kayu dalam satu suku secara umum mempunyai karakteristik fisik dan anatomis yang relatif sama dan hanya dapat ditemukan sedikit perbedaannya. Secara makroskopis keduanya dapat dibedakan dari warna kayu, wangi dan kenampakan kayunya. Kayu papi berwarna lebih gelap, nampak berminyak (mengilap), relatif kurang harum dan ada kesan bau asam semut sehingga seringkali kayu papi disebut juga dengan "cendana semut".

Tabel 1. Perbandingan morfologi kayu papi dengan cendana

Table 1. Morphological comparison between shrub sandalwood and sandalwood

\begin{tabular}{|c|c|c|}
\hline Aspek (Aspects) & Cendana (Sandalwood) & Papi (Shrub sandalwood) \\
\hline $\begin{array}{l}\text { Bentuk daun } \\
\text { (Leaf shape) }\end{array}$ & $\begin{array}{l}\text { Daun tunggal, berhadapan, agak bersilangan, tidak } \\
\text { berstipula, berbentuk elips (oblong) 3,5-5,25 x 2-3 } \\
\text { cm, panjang tangkai } 0,75-1 \mathrm{~cm} \text {, tepi daun sedikit } \\
\text { bergelombang* }^{*}\end{array}$ & $\begin{array}{l}\text { Daun tunggal, panjang tangkai } 2-14 \mathrm{~mm} \text {, } \\
\text { berbentuk elips atau bulat telur terbalik ukuran } \\
\text { sampai } 14 \mathrm{~cm} \times 8,5 \mathrm{~cm} \text { dengan tulang daun } \\
\text { melengkung ujung dan pangkal daun runcing }\end{array}$ \\
\hline $\begin{array}{l}\text { Batang } \\
(\text { Stem })\end{array}$ & $\begin{array}{l}\text { Batang berbentuk bulat, dapat mencapai diameter } \\
40 \mathrm{~cm} \text {, agak berlekuk, tanpa akar banir, perakaran } \\
\text { tunggang, dengan akar mampu menjadi akar } \\
\text { trubusan, beralur dangkal dengan kulit batang } \\
\text { relatif tipis }\end{array}$ & $\begin{array}{l}\text { Batang berbentuk bulat, berwarna coklat gelap } \\
\text { kehitaman dengan alur relatif lebih dalam dari } \\
\text { cendana, kulit terkelupas, dapat mencapai } 40 \mathrm{~cm} \text {, } \\
\text { dengan kulit batang yang agak tebal dan apabila } \\
\text { dilukai kulit batangnya bertekstur }\end{array}$ \\
\hline $\begin{array}{l}\text { Buah } \\
\text { (Fruit) }\end{array}$ & $\begin{array}{l}\text { Buah batu (drupe) berbentuk bola, berukuran kecil } \\
1 \text { x } 0,75 \mathrm{~cm} \text { diameternya, biji coklat muda } \\
\text { kekuningan, terdapat satu biji, biasanya dengan sisa } \\
\text { stilus yang pendek* }\end{array}$ & $\begin{array}{l}\text { Buah batu (drupe) agak lebih besar dari cendana } \\
\text { (di Timor) dan tangkai buah berkembang seperti } \\
\text { daging buah (fleshy) berwarna merah kehitaman } \\
\text { (edible) }\end{array}$ \\
\hline
\end{tabular}

Sumber (Source): Adriyanti (1989). 


\section{Aspek regulasi}

Kayu papi mempunyai potensi secara ekonomi namun kurang didukung regulasi yang memadai. Hal ini berpotensi mengancam kelestarian di habitat alaminya. Beberapa pemerintah daerah telah melakukan formalisasi aturan berkaitan dengan tata niaga kayu, antara lain: 1) Pemda Belu dengan penerbitan SK Bupati tentang retribusi khusus; 2) Pemda Sumba Barat dengan penerbitan peraturan mengenai jangka waktu penerbitan surat ijin pengiriman kayu dan 3) Pemerintah Kabupaten Sikka sejak tahun 2012 telah melakukan moratorium ijin pengiriman kayu papi. Secara rinci tata kelola cendana dan kayu papi dapat dilihat pada Tabel 2.

Formalisasi kebijakan ini bukan tanpa kendala, penerapan SK Bupati Belu mengenai penerapan retribusi pengangkutan kayu papi, hal ini juga dimaksudkan untuk melakukan moratorium penebangan. Namun karena menimbulkan informasi yang tidak sinkron mengenai besaran tarif sehingga meresahkan masyarakat, akhirnya peraturan tersebut dicabut atas masukan beberapa pihak. Langkah yang ditempuh oleh Dinas Kehutanan Kabupaten Sumba Barat lebih moderat namun efektif untuk menahan laju eksploitasi dalam beberapa sisi. Pemda melalui Dinas Kehutanan hanya menerbitkan surat ijin pengiriman kayu pada bulan-bulan di musim kemarau, dengan kuota tertentu dan dalam jangka waktu dua minggu sehingga tidak ada pengiriman kayu yang sifatnya rutin. Hal ini seperti soft moratorium penebangan sekaligus menerapkan asas jangka benah dan jatah tebangan. Apabila peraturan ditegakkan dengan konsisten maka dengan sendirinya laju degradasinya akan tertangani. Asumsi ini didasarkan atas: 1) sebaran alami kayu papi mayoritas ada di dalam kawasan hutan (Umroni et al., 2012) yang secara normatif ada aturan yang melekat tentang larangan izin penebangan dan 2) kayu papi merupakan komoditas perdagangan antar pulau yang memerlukan dokumen Surat Keterangan Sahnya Hasil Hutan (SKSHH) di mana prosedurnya ditata secara hierarki dan membutuhkan verifikasi lapangan.

\section{B. Kesenjangan Kayu Papi dan Cendana}

\section{Publikasi ilmiah}

Hasil penelusuran pustaka riset tentang cendana dan kayu papi diperoleh pustaka sebanyak 273 studi tentang cendana dan sembilan pustaka tentang kayu papi dari Google Scholar dan sebanyak 46 publikasi tentang cendana serta satu publikasi tentang kayu papi dari EBSCO Host seperti pada Tabel 3.

Dari Tabel 3 diketahui bahwa terjadi kesenjangan penelitian yang signifikan antara cendana dan kayu papi. Hal ini dapat terjadi karena cendana lebih populer dan merupakan material parfum yang paling awal digunakan (Bhat et al., 2006) serta telah diperdagangkan dari kepulauan Sunda Kecil (Timor, Sumba) sejak abad ke-3 Masehi (Oyen \& Huan Dun, 1999). Publikasi kayu

Tabel 2. Komparasi kayu papi dengan cendana dalam aspek tata kelola

Table 2. Comparison between shrub sandalwood and sandalwood in regulation aspect

\begin{tabular}{llc}
\hline Aspek (Aspects) & Cendana (Sandalwood) & Papi (Shrub sandalwood) \\
\hline Peraturan & - Perda Timor No. 4 Tahun 1953, Perda No. & - Kabupaten Belu yang membuat regulasi \\
(Regulation) & 11/PD/1966, Perda No. 8 Tahun 1968, Perda No. 7 & khusus tentang kayu papi, substansinya \\
& Tahun 1974, Perda No. 17 Tahun 1974, Perda No. 7 & tentang besaran tarif retribusi, namun \\
& Tahun 1980, Perda No. 16 Tahun 1986, Kep utusan & SK Bupati ini telah dicabut. \\
& Gubernur No. 2 Tahun 1996, substansinya tentang & - Kabupaten Sikka sejak 2012 melakukan \\
& penguasaan pemerintah atas cendana* & moratorium ijin penebangan kayu Papi \\
& - Instruksi Gubernur No. 7 Tahun 1997 tentang & \\
& moratorium penebangan selama lima tahun & \\
- Perda No. 2 Tahun 1999 yang membatalkan Perda & \\
& No. 16 Tahun 1986, sekaligus pengembalian hak \\
& cendana kepada masyarakat \\
- Perda di tingkat kabupaten (Sumba Barat, Sumba & \\
& Timur, TTS, TTU, Belu) \\
\hline
\end{tabular}

Sumber (Sources): *Raharjo (2013). 
Tabel 3. Klasifikasi perbandingan jumlah penelitian kayu papi dan cendana Table 3. Classification of research number between shrub sandalwood and sandalwood

\begin{tabular}{|c|c|c|c|c|}
\hline \multirow[b]{2}{*}{ Aspek $(A s p e c t)$} & \multicolumn{2}{|c|}{ Cendana (Sandalwood) } & \multicolumn{2}{|c|}{ Kayu papi (Shrub sandalwood) } \\
\hline & $\begin{array}{l}\text { Kategori } \\
\text { (Category) }\end{array}$ & Keterangan (Remark) & $\begin{array}{l}\text { Kategori } \\
\text { (Category) }\end{array}$ & Keterangan (Remark) \\
\hline Silvikultur (Silviculture) & SB & $\begin{array}{l}\text { GS: } 83 \text { publikasi } \\
\text { EH: } 14 \text { publikasi }\end{array}$ & SS & EH: 1 publikasi \\
\hline $\begin{array}{l}\text { Sosial ekonomi (Social } \\
\text { economic) }\end{array}$ & S & $\begin{array}{l}\text { GS: } 5 \text { publikasi } \\
\text { EH: } 1 \text { publikasi }\end{array}$ & SS & EH, GS: 0 publikasi \\
\hline $\begin{array}{l}\text { Ekologi konservasi (Ecology } \\
\text { conservation) }\end{array}$ & S & $\begin{array}{l}\text { GS: } 6 \text { publikasi } \\
\text { EH: } 6 \text { publikasi }\end{array}$ & SS & EH, GS: 0 publikasi \\
\hline Kandungan (Content) & SB & $\begin{array}{l}\text { GS: } 74 \text { publikasi } \\
\text { EH: } 9 \text { publikasi }\end{array}$ & $S$ & $\begin{array}{l}\text { EH: } 0 \text { publikasi } \\
\text { GS: } 7 \text { publikasi }\end{array}$ \\
\hline Pemuliaan (Tree improvement) & B & $\begin{array}{l}\text { GS: } 35 \text { publikasi } \\
\text { EH: } 5 \text { publikasi }\end{array}$ & SS & EH, GS: 0 publikasi \\
\hline Fisiology (Physiology) & $\mathrm{C}$ & $\begin{array}{l}\text { GS: } 23 \text { publikasi } \\
\text { EH: } 6 \text { publikasi }\end{array}$ & SS & GS: 2 publikasi \\
\hline $\begin{array}{l}\text { Hama penyakit (Pest and } \\
\text { disease) }\end{array}$ & SB & $\begin{array}{l}\text { GS: } 47 \text { publikasi } \\
\text { EH: } 5 \text { publikasi }\end{array}$ & SS & EH, GS: 0 publikasi \\
\hline Total (Summary) & & $\begin{array}{l}\text { GS: } 273 \text { publikasi } \\
\text { EH: } 46 \text { publikasi }\end{array}$ & $\begin{array}{l}\text { GS: } 9 \text { publik } \\
\text { EH: } 1 \text { publik }\end{array}$ & \\
\hline
\end{tabular}

Keterangan (Remarks):

SB, sangat banyak > 50 publikasi; B, banyak 30-50 publikasi; C, cukup 15-29 publikasi; S, sedikit 5-14 publikasi; SS, sangat sedikit $<5$ publikasi; GS, Google schoolar; EH, EBSCO host (SB, very plenty >50 publications; B, plenty 30-50 publications; C, modest $15-29$ publications; S, scarce 5-14 publications; SS, very scarce < 5 publcations; GS, Google schoolar; EH, EBSCO host).

papi paling banyak tentang kandungan dan efektivitasnya sebagai obat tuberculosis (Koch, 2009). Studi ini relatif masih baru dan belum ada yang melakukan studi tentang kandungan serta minyak yang dihasilkan. Publikasi tentang cendana didominasi studi tentang aspek silvikultur dengan jumlah publikasi yang ditemukan dari Google Scholar dan EBSCO Host berturut-turut sebesar 83 dan 14 publikasi. Kemudian lebih dari 70 publikasi mempelajari kandungan bahan ekstraktif dan manfaat yang terkandung dari cendana. Secara komparasi lebih dari 300 publikasi ilmiah mempelajari tentang cendana dari beragam aspek sedangkan publikasi mengenai kayu papi hanya ditemukan sebanyak 10 publikasi. Hal ini sangat kontras sehingga diperlukan upaya ekstra untuk mengejar kesenjangan ini dalam rangka meningkatkan nilai tambah (value added) kayu papi.

\section{Upaya konservasi}

Belajar dari pengalaman cendana di mana rekaman genetik cendana yang lebih lengkap dan representatif ada di luar NT'T, maka diperlukan langkah antisipasi untuk menjaga keragaman genetik kayu papi. Upaya konservasi keduanya secara ex-situ (preventif) dan regulasi (preemptive) secara rinci disajikan pada Tabel 4.

Plot konservasi cendana di Oelbubuk mempunyai koleksi lebih dari 380 tanaman induk, sudah berproduksi namun tanpa rekam genetik yang jelas. Plot konservasi di Watusipat Gunung Kidul terdiri atas 13 provenan dari NTT dan satu provenan dari Gunung Kidul, tahun tanam 2002 (Fiani et al., 2012). Belajar dari pengalaman cendana di mana terdapat kelemahan dalam hal perekaman genetik (di Oelbubuk) dan tahun awal pengoleksian materi genetik (Watusipat) seharusnya saat ini dimulai upaya konservasi genetik kayu papi di NT'T.

Mengingat laju eksploitasi yang terus berlangsung berpotensi menimbulkan degradasi keragaman genetik di habitat alaminya, Balai Penelitian Kehutanan Kupang berusaha mengoleksi 52 famili kayu papi dari Pulau Timor dan 10 famili dari Pulau Sumba, yang saat ini dalam tahap pembangunan. Menurut Namof et al. (2010) untuk melaksanakan konservasi jenis (ex-situ) 
Tabel 4. Perbandingan status dan upaya konservasi antara kayu papi dan cendana

Table 4. Comparison status and consevation attempts between sandalwood and shrub sandalwood

\begin{tabular}{|c|c|c|}
\hline Aspek (Aspects) & Cendana (Sandalwood) & Papi (Shrub sandalwood) \\
\hline $\begin{array}{l}\text { Plot konservasi } \\
\text { (Conservation plot) }\end{array}$ & $\begin{array}{l}\text { - Plot konservasi Balai Penelitian Kehutanan Kupang di Desa } \\
\text { Oelbubuk di TTS } \\
\text { - Plot konservasi Balai Besar Penelitian Bioteknologi dan } \\
\text { Pemuliaan Tanaman Hutan Yogyakarta di Watusipat Gunung } \\
\text { Kidul } \\
\text { - Plot konservasi Balai Penelitian Kehutanan Kupang di Stasiun } \\
\text { Banamlaat Kefamenanu TTU } \\
\text { - Kebun benih Kian Rai Ikun (KB-KRI) yang dikelola oleh LIPI di } \\
\text { Kabupaten Belu1 }\end{array}$ & $\begin{array}{l}\text { Plot konservasi ex-situ Balai } \\
\text { Penelitian Kehutanan } \\
\text { Kupang di Soe (dalam } \\
\text { tahap pembangunan) }\end{array}$ \\
\hline $\begin{array}{l}\text { Sumber Benih } \\
\text { (Seed sources) }^{2}\end{array}$ & $\begin{array}{l}\text { - Lew Oeleng, Kabupaten Lembata, luas 2,5 ha (TBT) } \\
\text { - Meredadana di Kabupaten Sumba Barat Daya, luas 2,03 ha (TBT) } \\
\text { - Kampung Wotok, Kabupaten Manggarai, luas 0,75 ha (TBT) } \\
\text { - Adang Kokar, Kabupaten Alor, luas 5,55 ha (TBT) } \\
\text { - Pagomogo, Kabupaten Nagekeo, luas 4,09 ha (TBT) } \\
\text { - Noinbila, Kabupaten TTS, luas 1,6 ha (TBT) } \\
\text { - HTI Polen, Kabupaten TTS, luas 0,1 ha (TBT) } \\
\text { - Pusu, Kabupaten TTS, luas 1,17 ha (TBT) } \\
\text { - Netpala-Oelbubuk, Kabupaten TTS, luas 4,09 ha (APB) } \\
\text { - Oebatu, Kabupaten Rote Ndao, luas 5,34 ha (TBT) }\end{array}$ & Belum tersedia \\
\hline Status (Status) & $\begin{array}{l}\text { - Vurnerable versi IUCN, sejak tahun } 1998^{3} \\
\text { - Boleh diperdagangkan pasca moratorium tebangan tahun 2002- } \\
2007 \text { oleh Pemerintah Provinsi NTT. }\end{array}$ & Tidak tersedia \\
\hline
\end{tabular}

Sumber (Sources): ${ }^{1}$ Wawo (2008), ${ }^{2}$ BPTH Bali-Nusra dalam Sumardi et al. (2014), ${ }^{3}$ IUCN (2013).

Keterangan (Remarks): TBT, Tegakan Benih Tersertifikasi; APB, Area Produksi Benih (IS, Identified Stand; SPA, Seed Production Area).

diperlukan sekurangnya 15 individu yang berasal dari tiga populasi untuk mempertahankan keragaman genetiknya. Dengan demikian hasil eksplorasi materi genetik yang dilaksanakan sudah representatif untuk kegiatan konservasi ex-situ. Status kayu papi dan cendana menurut IUCN berbeda, cendana termasuk daftar redlist spesies dengan status rentan (vulnerable) sedangkan kayu papi data tidak tersedia. Konsekuensinya adalah, cendana dibatasi perdagangannya namun kayu papi yang mempunyai kerentanan hampir sama, dapat diperdagangkan secara bebas.

\section{Informasi silvikultur}

Beberapa suku Santalaceae dikenal sebagai spesies semiparasit (bemyparasitic) yang melakukan simbiosis secara parasit dengan membentuk baustoria dengan akar tanaman lain, sehingga dalam usaha budidaya kedua spesies ini diperlukan adanya penambahan tanaman yang berfungsi sebagai inang. Komparasi keduanya dalam aspek budidaya dan proses fisiologisnya disajikan pada Tabel 5 .

Dari Tabel 5 terlihat adanya gap atau rentang yang lebar antara penelitian kayu papi dengan penelitian cendana. Penelitian cendana lebih unggul (advance) dalam berbagai studi karena keunggulan komparatifnya dan lebih populer dalam perdagangan. Potensi pengembangan kayu papi terutama diperlukan untuk menjawab persoalan budidaya, kandungan essential oil-nya dan uji fitokimianya untuk menguji kandungan unsur yang bermanfaat secara medis. 
Tabel 5. Komparasi kayu papi dengan cendana dalam aspek budidaya

Table 5. Silviculture comparison of shrub sandalwood and sandalwood)

\begin{tabular}{|c|c|c|}
\hline Perbandingan (Comparison) & Cendana (Sandalwood) & Papi (Shrub sandalwood) \\
\hline Pembungaan (Flowering) & Juni-Oktober $^{1}$ & Tidak tersedia \\
\hline Polinator (Polinator) & Lebah madu (Apis mellifera sp.) dan semut ${ }^{1}$ & Tidak tersedia \\
\hline $\begin{array}{l}\text { Jumlah biji/kilogram } \\
\text { (Amount of seed/kig }\end{array}$ & $5.000-8.000^{2}$ & Tidak tersedia \\
\hline Skarifikasi (Pre treatment) & $\begin{array}{l}\text { Mekanis atau direndam dalam larutan giberelic } \\
\text { acid }^{3}\end{array}$ & $\begin{array}{l}\text { Mekanis (memecah lapisan biji) dan } \\
\text { direndam air dingin }{ }^{5}\end{array}$ \\
\hline Inang (Host plant) & $\begin{array}{l}\text { Primer: Acacia spp., Alternathera spp., } \\
\text { Amaranthus spp., Breynia cerrua, Cajanus cajan, } \\
\text { Capsicum spp. } \\
\text { Sekunder: Pterocarpus, Acacia, Cassia, } \\
\text { Paraserianthes, Casuarina, Sesbania }{ }^{4}\end{array}$ & $\begin{array}{l}\text { Primer: Althenantera sp., Cajanus cajan, } \\
\text { Sesbania grandiflora, Sauropus }{ }^{6} \\
\text { Sekunder: Pethalostigma spp., Chantium } \\
\text { spp., Terminalia spp., Callistis sp }{ }^{2}\end{array}$ \\
\hline Sebaran (Distribution) & $\begin{array}{l}\text { Indonesia: Timor, Flores, Alor, Sumba, India } \\
\text { 0-1.4 } \\
000 \text { mdpl namun optimal } 600-900 \mathrm{mdpl}^{2}\end{array}$ & $\begin{array}{l}\text { Jawa: Puger, Besuki, Bondowoso, } \\
\text { Baluran, Sumenep, Kangean; Bali; } \\
\text { Sumbawa: Flores, Mangaarai, } \\
\text { Manggarai Barat, Pulau Rinca, } \\
\text { Sumba; Timor; Sulawesi: Pangka- } \\
\text { djene, Selayar; Maluku: Pulau Obi, } \\
\text { Pulau Aru, Kei, Ternate, Halmahera; } \\
\text { Papua; PNG; Filipina }{ }^{7} \\
\text { 0-600 } \text { mdpl }^{7} \text { dan 0-1.200 } \text { mdpl }^{5}\end{array}$ \\
\hline $\begin{array}{l}\text { Kandungan minyak } \\
\text { (Essensial oil) }\end{array}$ & $\begin{array}{l}\text { Santalol: }(Z)-\alpha \text {-santalol }(45-47 \%),(Z)-\beta- \\
\text { santalol }(20-30 \%)^{2}\end{array}$ & Tidak tersedia \\
\hline $\begin{array}{l}\text { Kegunaan } \\
\text { (Utility) }\end{array}$ & Parfum, kosmetik dan obat-obatan & $\begin{array}{l}\text { Bahan kerajinan dan obat TBC dari } \\
\text { hasil derivasinya dalam bentuk } \\
\text { Exocarpic acid }\end{array}$ \\
\hline Etnobotani (Ethnobotany) & $\begin{array}{l}\text { Gagang keris dan obat tradisional (sakit perut, } \\
\text { gonorrhoea) }\end{array}$ & $\begin{array}{l}\text { Kulit batangnya untuk menginang, } \\
\text { kayunya: tiang utama rumah, pe- } \\
\text { nambat ternak, gangsing (mainan) dan } \\
\text { penumbuk padi }\end{array}$ \\
\hline
\end{tabular}

Sumber(Sources): ${ }^{1}$ Baskorowati (2011), ${ }^{2}$ Oyen, (1999), ${ }^{3}$ Nagaveni \& Srimathi 1980, 1981, 1985b; Mahdi, 1986 ; Nagaveni et al., 1989 dalam Neil (1990), ${ }^{4}$ Applegate at al.(1990), ${ }^{5}$ Umroni et al. (2012), ${ }^{6}$ Umroni et al. (2013), ${ }^{7}$ Susiarti (2005), ${ }^{8}$ Koch (2009).

\section{Perbandingan Kayu Papi dan Cendana}

\section{Produksi dan harga kayu}

Eksploitasi kayu papi di NTT terus mengalami kenaikan. Daftar Gabungan Laporan Produksi Hasil Hutan Olahan Bukan Kayu (DGLPHHOBK) dari tahun 2009 sampai dengan 2012 (Dinas Kehutanan Provinsi NTT, 2012) menunjukkan pengiriman kayu papi dari NTT mengalami peningkatan sedangkan pengiriman hasil olahan cendana mengalami penurunan, seperti nampak pada Tabel 6. Kayu papi dan cendana merupakan komoditas yang dapat saling menyubstitusi karena keduanya dieksploitasi untuk tujuan mendapatkan kayu harumnya.

Dari Tabel 6 diketahui bahwa kecenderungan kayu papi digunakan sebagai pengganti cendana semakin meningkat dilihat dari volume pengiriman kayu papi keluar dari NTT. Meskipun ada kecenderungan peningkatan produksi cendana namun secara komparatif produksi kayu harum dari NTT dalam empat tahun terakhir masih didominasi oleh kayu papi dengan persentase sebesar $71,5 \%$ sementara sisanya $28,5 \%$ berasal dari cendana. 
Tabel 6. Perbandingan produksi cendana dan kayu papi di NTT

Table 6. Production comparison between sandalwood and shrub sandalwood in NTT

\begin{tabular}{cccc}
\hline $\begin{array}{c}\text { Tahun } \\
(\text { Year })\end{array}$ & $\begin{array}{c}\text { Produksi kayu cendana } \\
\text { (Sandahwood production) } \\
\text { (Ton) }\end{array}$ & $\begin{array}{c}\text { Produksi gubal cendana } \\
\text { (Sandahwood/sapwood production) } \\
\text { (Ton) }\end{array}$ & $\begin{array}{c}\text { Produksi kayu papi } \\
\text { (Shrub sandalwood production) } \\
\text { (Ton) }\end{array}$ \\
\hline 2009 & 19,53 & - & 48,60 \\
2010 & 20,52 & - & 3,30 \\
2011 & 416,42 & 266,3 & $2.217,12$ \\
2012 & 210,12 & 191,1 & 536,53 \\
\hline Jumlah & $666,59(16,9 \%)$ & $457,4(11,6 \%)$ & $2.805,55(71,39 \%)$ \\
$($ Summary) & & & \\
\hline
\end{tabular}

Sumber (Source): Dinas Kehutanan Provinsi Nusa Tenggara Timur (2012).

Tabel 7. Perbandingan nilai ekonomi kayu papi dengan cendana di tingkat lokal (Timor)

Table 7. Economic value comparison between shrub sandalwood and sandalwood in Timor

\begin{tabular}{|c|c|c|}
\hline Perbandingan (Comparison) & Cendana (Sandalwood) & Papi (Shrub sandalwood) \\
\hline Berat jenis (Specific gravity) & $0,9-1,14^{\mathrm{d}}$ dan $0,77-0,94^{\mathrm{f}}$ & $1,05-1,20^{\mathrm{e}, \mathrm{c}}$ dan $0,99-1,14^{\mathrm{f}, \mathrm{e}}$ \\
\hline Berat per $\mathrm{m}^{3}$ (Weight per $\mathrm{m}^{3}$ ) & $900-1.140 \mathrm{~kg} / \mathrm{m}^{3}$ & $1.050-1.200 \mathrm{~kg} / \mathrm{m}^{3}$ \\
\hline Harga lokal, teras (Local price, heartwood) ${ }^{a}$ & Rp $250.000-500.000 / \mathrm{kg}^{\mathrm{b}}$ & $\mathrm{Rp} 3.000 / \mathrm{kg}$ \\
\hline Gubal (Sapwood) c & $\mathrm{Rp} 2.000-3.000 / \mathrm{kg}$ & Tidak tersedia \\
\hline Nilai ekonomi, teras (Economic value, heartwood) & Rp 225-285 juta/kubikg & Rp 3,15-3,6 juta/kubik \\
\hline Gubal (Sapwood) & Rp 1,8-2,7 juta/kubik & Tidak tersedia \\
\hline Riap (Increament) & $0,5-1 \mathrm{~cm} /$ tahun $^{\mathrm{d}}$ & Tidak tersedia \\
\hline
\end{tabular}

Keterangan (Remarks):

${ }^{a}$ Data tahun 2013 di Pulau Timor di tingkat petani secara rata-rata.

${ }^{\mathrm{b}}$ Harga cendana dengan kualitas teras prima, nilainya bervariasi dan cenderung seperti barang mewah sehingga harganya bisa menyesuaikan dengan minat kolektor.

'Kayu papi menjadi preferensi masyarakat untuk pilar utama rumah adat (lopo) karena kekuatannya, sebagai ilustrasi kayu besi atau ulin (Eusideroxylon zwagery) mempunyai berat jenis rata rata 1,05 sehingga kayu papi relatif sama kuat dengan kayu ulin.

'Oyen \& Huan Dun (1999).

${ }^{\mathrm{e}}$ Heyne (1987).

${ }^{\mathrm{f}}$ Seng (1990).

${ }^{g}$ Sumanto et al. (2011).

Menurut Heyne (1987) kayu papi termasuk dalam kayu kelas kuat I dan kelas awet II dengan berat jenis antara 1,05-1,20 sedangkan Seng (1990) mengategorikannya dalam kelas kuat I dan kelas awet II namun dengan berat jenis antara 0,99-1,14. Sementara itu, Seng (1990) menyebutkan cendana mempunyai kelas kuat I-II dan kelas awet II dengan berat jenis antara $0,77-0,94$. Oyen \& Huan Dun (1999) menyebutkan berat jenis cendana berkisar antara 0,9-1,14. Berdasarkan ilustrasi dari berat jenis keduanya dapat diketahui nilai ekonomi per kubiknya sebagaimana disajikan pada Tabel 7 .

Rentang harga jual yang sangat jauh antara kayu papi (Rp 3,15 juta/m²) dengan kayu cendana (Rp
225 juta $/ \mathrm{m}^{3}$ ) mendorong eksploitasi yang besar. Hal ini diperkuat dengan kemiripan keduanya dalam aroma, tekstur dan secara mikroskopis hampir tidak bisa dibedakan. Terlebih lagi efektivitas sortimen kayu papi yang dapat diperjualbelikan (merchantable) sangat bervariasi ukurannya. Bagian akar yang mempunyai kandungan kayu teras yag lebih tinggi (Bhat et al., 2006) serta sortimen terkecil yang dapat dijual sampai pada ukuran balok $2 \mathrm{~cm} \times 2 \mathrm{~cm} \times 12 \mathrm{~cm}$ dan stik pensil sepanjang $5 \mathrm{~cm}$. Hal ini menjadikan kayu papi tidak menghasilkan residu dalam prosesnya, bahkan serpihannya dapat dijual.

Pemanfaatan kayu papi yang nyaris tanpa meninggalkan sisa, meningkatkan risiko 
kepunahan karena potensi permudaan alaminya (trubusan) sangat minim. Ukuran sortimen yang relatif kecil dan mudah dikemas memudahkan dalam pengangkutan yang pada akhirnya menyulitkan pengawasan terhadap peredarannya.

\section{Kelimpahan tanaman}

Peningkatan produksi kayu papi berbanding lurus dengan tingkat eksploitasi kayu papi, baik di lahan milik maupun di kawasan hutan. Survei yang dilakukan tahun 2012 di beberapa kawasan hutan di Pulau Timor menunjukkan bahwa telah terjadi over eksploitasi kayu papi. Hal ini terlihat dari hasil analisis vegetasi di mana kelimpahan kayu papi untuk kelas diameter pohon sudah sangat berkurang di lokasi penelitian (Tabel 8).

Data tersebut sinkron dengan data distribusi sebaran kabupaten penghasil kayu papi seperti pada Tabel 9, di mana kabupaten dengan persentase produksi kayu papi yang tinggi, pada saat yang sama tingkat kelimpahan di habitat alaminya mengalami penurunan. Sebagai contoh di Kabupaten Belu, tingkat kelimpahan alami kayu papi paling rendah dibanding kabupaten lainnya, sementara itu tingkat produksinya mengalami kenaikan pada tahun 2011 dan 2012. Sedangkan di Kabupaten TTS, kontinuitas pengiriman kayu papi yang relatif terjaga karena tingkat kelimpahannya paling tinggi secara komparatif.

Tabel 9 menunjukkan adanya indikasi kegiatan eksploitasi kayu papi bergeser dari Pulau Timor ke luar Pulau Timor. Pada tahun 2009-2010, keseluruhan pengiriman $(100 \%)$ kayu papi berasal dari Pulau Timor, namun mulai tahun 2011 bergeser ke Flores dengan komposisi Kabupaten Sikka, Manggarai Barat dan Manggarai Timur dengan persentase berturut-turut adalah $0,8 \%$, 1,3\% dan 2,9\%. Pada tahun 2012, eksploitasi kayu papi dari Pulau Timor hanya sebesar 68\%, sisanya 32\% dipenuhi dari Kabupaten Sikka di Flores. Pergeseran ini mengindikasikan adanya penurunan kelimpahan alami kayu papi dan eksploitasi yang terus berpindah ke kabupaten lain yang masih relatif melimpah dan longgar regulasinya.

Tabel 8. Tabel analisis vegetasi kayu papi untuk tingkatan pohon dan tiang di Pulau Timor Table 8. Vegetation analyses of shrub sandalwood at trees and poles classification

\begin{tabular}{clcc}
\hline No. & \multicolumn{1}{c}{ Lokasi (Location) } & $\begin{array}{c}\text { INP Tingkatan pohon } \\
\text { (IV of trees) }\end{array}$ & $\begin{array}{c}\text { INP Tingkatan tiang } \\
\text { (IV of poles) }\end{array}$ \\
\hline 1 & Kobalima, Belu & - & - \\
2 & Niba-Niba, TTU & - & 31,69 \\
3 & Lapeom, TTU & - & - \\
4 & Oelusun, TTU & - & - \\
5 & TTS (Bikekneno, Biloto dan Bijeli) & 9,52 & 58,77 \\
6 & Mutis, TTS & 32,82 & 50,63 \\
7 & Camplong Kabupaten Kupang & - & - \\
\hline
\end{tabular}

Tabel 9. Distribusi produksi kayu papi di NTT berdasarkan kabupaten Table 9. The distribution of shrub sandalwood production in NTT based on regency

\begin{tabular}{|c|c|c|c|c|c|}
\hline No. & Lokasi (Location) & $\begin{array}{l}2009 \\
\text { ('Ton) }\end{array}$ & $\begin{array}{l}2010 \\
\text { (Ton) }\end{array}$ & $\begin{array}{l}2011 \\
\text { (Ton) }\end{array}$ & $\begin{array}{l}2012 \\
\text { (Ton) }\end{array}$ \\
\hline 1 & Kabupaten Belu & 0 & 0 & 463 & 145,1 \\
\hline 2 & Kabupaten TTU & 0 & 0 & 30 & 90,5 \\
\hline 3 & Kabupaten TTS & 0 & 3,3 & 281,8 & 36,1 \\
\hline 4 & Kota Kupang & 0 & 0 & 275,1 & 91,2 \\
\hline 5 & Kabupaten Kupang & 48,60 & 0 & 1.056 & 0 \\
\hline 6 & Kabupaten Manggarai Timur & 0 & 0 & 63,2 & 0 \\
\hline 7 & Kabupaten Manggarai Barat & 0 & 0 & 30 & 0 \\
\hline 8 & Kabupaten Sikka & 0 & 0 & 17,5 & 173,5 \\
\hline \multicolumn{2}{|c|}{ Total produksi NTT (Amount of NTTproduction) } & 48,60 & 3,3 & $2.217,12$ & 536,53 \\
\hline \multicolumn{2}{|c|}{ Total produksi Pulau Timor (Amount of Timorproduction)* } & 48,60 & 3,3 & $2.105,9$ & 362,9 \\
\hline \multicolumn{2}{|r|}{$\begin{array}{l}\text { Persentase dari Pulau Timor terhadap produksi NTT (Proportion of Timor } \\
\text { toward NTT production) }(\%)\end{array}$} & 100 & 100 & 95 & 68 \\
\hline
\end{tabular}

Sumber (Source): Dinas Kehutanan Provinsi NTT, 2012 (Data diolah). 
Tabel 10. Indeks nilai penting cendana di tiga kabupaten di Pulau Timor

Table 10. Importance value at three regencies in Timor island

\begin{tabular}{cccc}
\hline \multirow{2}{*}{ Kabupaten (Regencies) } & \multicolumn{3}{c}{ INP Cendana (Importance value of Sandalwood } \\
\cline { 2 - 4 } & Pohon (Trees) & Tiang (Poles) & Sapihan (Saplings) \\
\hline Belu & 209,31 & 194,85 & 208,43 \\
TTS & 202 & 223,85 & 178,53 \\
TTU & 60 & 234 & 233,41 \\
\hline
\end{tabular}

Sumber (Source): Kurniawan et al. (2013).

Data tersebut menjelaskan terjadinya peningkatan eksploitasi kayu papi di dalam kawasan hutan, mengingat kayu papi belum banyak dibudidayakan oleh masyarakat. Diperkirakan eksploitasi kayu papi akan meningkat dan bergeser ke pulau lain di NT'T, mengingat kesenjangan harga antara cendana dan kayu papi sangat tinggi dan keduanya dapat saling menggantikan. Kelimpahan cendana di Pulau Timor yang ada saat ini mayoritas berada di lahan milik. Penelitian yang dilakukan oleh Kurniawan et al. (2013) menunjukkan bahwa kelimpahan cendana pada tingkatan pohon, tiang dan sapihan relatif seimbang, kecuali di Kabupaten TTU, secara detail dapat dilihat pada Tabel 10 .

Tabel 10 menunjukkan bahwa cendana masih dipertahankan oleh masyarakat di lahan mereka. Secara umum kelimpahan di tingkat sapihan mengindikasikan adanya kesadaran masyarakat untuk menanam kembali cendana setelah pernah ditinggalkan karena efek kebijakan yang menjadikan cendana di lahan milik sebagiannya sebagai milik pemerintah. Namun kelimpahan cendana di hutan hampir hilang dan berganti dengan cendana di lahan milik yang lebih mudah dijaga dan dipelihara. Menurut Dinas Kehutanan Kabupaten T'TS, sebagai daerah terbesar penghasil cendana, pada tahun 2010, disebutkan bahwa pasca moratorium penebangan cendana tahun 2007 diperlukan setidaknya 10 tahun untuk mendapatkan cendana yang siap panen. Kelangkaan cendana ini ikut berkontribusi terhadap berkurangnya kayu papi di habitat alaminya.

\section{KESIMPULAN DAN SARAN}

\section{A. Kesimpulan}

Kayu papi dan cendana adalah dua jenis kayu harum yang saling menyubstitusi. Kelestarian keduanya di habitat alaminya terancam karena eksploitasi yang berlebihan. Kondisi cendana dan kayu papi berbeda nyata: Pertama, kesenjangan informasi dan konservasi kayu papi dan cendana adalah nyata. Terdapat 319 publikasi ilmiah yang memuat informasi tentang cendana dan ada empat plot/kebun konservasi yang dibangun dalam rangka konservasi cendana. Sementara itu, hanya ada 10 publikasi ilmiah yang memuat informasi tentang kayu papi dan hanya ada satu plot konservasi kayu papi. Kedua, harga kayu papi (Rp 3,1 juta $/ \mathrm{m}^{3}$ ) lebih rendah dibanding harga kayu cendana (Rp 225 juta/m $\mathrm{m}^{3}$ ) dan rataan produksi kayu papi dalam empat tahun terakhir (700 $\mathrm{m}^{3} /$ tahun) lebih tinggi dibanding rataan produksi kayu cendana $\left(166 \mathrm{~m}^{3} /\right.$ tahun). Ketiga, kelimpahan kayu papi di beberapa daerah di Timor lebih rendah di-banding cendana. INP kayu papi pada tingkat tiang dan pohon di beberapa kawasan hutan secara berturut-turut adalah 31-57 dan 9-32, sedangkan INP cendana di lahan milik pada tingkat tiang dan pohon adalah 194-234 dan 60-209. Dengan kelimpahan tanaman lebih rendah dan produksi kayu lebih tinggi, kelestarian kayu papi lebih terancam dibanding cendana.

\section{B. Saran}

Konservasi kayu papi mendesak dilakukan. Hal ini dapat diupayakan dengan membangun plot konservasi ex-situ yang mengumpulkan keragaman genetik kayu papi dari beberapa populasi kayu papi di NTT secara lebih representatif, melaksanakan penelitian untuk menyusun paket teknologi budidaya dan meluncurkan kebijakan yang mengatur produksi dan peredaran kayu papi.

\section{UCAPAN TERIMA KASIH}

Penulis mengucapakan terima kasih kepada Balai Penelitian Kehutanan Kupang yang mendanai kegiatan penelitian ini, Bapak Hery Kurniawan, S. Hut., M.Sc. yang membantu analisis 
dalam metode penelitian, seluruh teknisi Balai Penelitian Kehutanan yang telah membantu kegiatan ini serta dewan redaksi dan editor yang telah membantu menyempurnakan naskah ini.

\section{DAFTAR PUSTAKA}

Adriyanti, D. T. (1989). Studi dendrologis cendana di Pulau Timor Nusa Tenggara Timur. (Skripsi). Universitas Gadjah Mada, Yogyakarta.

Applegate, G.B., Chamberlain, J., Daruhi, G., Feigelson, J.L., Hamilton, L., McKinnell, F. H., ..., \& Stemmerman, L. (1990). Sandalwood in the Pacific: A state-ofknowledge synthesis and summary from the April 1990 Symposium. Proceeding of the symposium on sandalwood in the pacific, Hawaii, April 9-11, 1990. Berkeley: Pacific Southwest Research Station USDA Forest Service.

IUCN. (2013). IUCN Red List of Threatened Species. (Version 2013.2). Prosiding Asian Regional Workshop (Conservation \& Sustainable Management of Trees, Viet Nam, August 1996. Diunduh dari www.iucnredlist.org. (8 Mei 2014).

Baskorowati, L. (2011). Flowering intensity and flowers visitors of Santalum album L. at ex-situ conservation plot, Watusipat, Gunung Kidul, Yogyakarta. Journal of Forestry Research,8(2),130-143.

Bhat, K.V., Balasundaran, M., \& Balagopalan, M. (2006). Identification of Santalum album and Osyris lanceolata through morphological and biochemical characteris-tics and molecular markers to check adulteration (Research report No. 307). Kerala: Forest Research Institute.

Cires, E., Yannick, D.S., Paul, G., Sazanne, S., Douglas, G., Sara, O., ..., \& Mariestephanie, S. (2013). Gap analyses to support ex-situ conservation of genetic diversity in Magnolia sp., a flagship group. Biodivers Conserv., 22(3), 567-590.

Dinas Kehutanan dan Perkebunan Kabupaten Timor Tengah Selatan. (2010). Inventarisasi tegakan cendana di Kabupaten Timor Tengah Selatan. Soe: Proyek International Tropical Timber Organization (ITTO) PD 459/07 Rev.1 (F).

Dinas Kehutanan Provinsi NT'T. (2012). Daftar gabungan laporan produksi hasil butan olahan bukan kayu (GLPHHO-BK) Provinsi NTT periode 2009-2012. Kupang: Dinas Kehutanan Provinsi NTTT.

Dumbois-Mueller, D. \& Ellenberg, H. (1974). Aims and methods of vegetation ecology. NY: John Willey and Son.

Fiani, A., Windyarini, E., \& Yuliah. (2012). Evaluasi kesehatan cendana (Santalum album Lin.) di kebun konservasi ex-situ Watu Sipat Gunung Kidul(Laporan Hasil Penelitian). Yogyakarta: Balai Besar Penelitian Bioteknologi dan Pemuliaan Tanaman Hutan.

Haffner, D. H. (1993). The quantity and quality of beartwood in two species of sandalwood. (Thesis). University of Melbourne.

Heyne, K. (1987). Tumbuban berguna Indonesia (Jilid IV). Edisi Terjemahan. Jakarta: Yayasan Sarana Wanajaya.

Koch, M. (2009). Mode action of exocarpic acid against mycobacterium tuberculosis. (Dissertation). University of Utah.

Kurniawan, H., Soenarno, \& Prasetyo, N. A. (2013). Kajian beberapa aspek ekologi cendana pada lahan masyarakat di Pulau Timor. Jurnal Penelitian Hutan dan Konservasi Alam, 10(1), 33-49.

Mandang, Y.I. (1988). Anatomi per-bandingan kayu cendana (Santalum album L.) dan exocarpus (Exocarpus latifolia R.Br.). Jurnal Penelitian HasilHutan, 5(6), 365-368.

Namof, S., Husby, C., Nolick, L., Franciseortega, J., Lewis, C.E., \& Grifith, M.P. (2010). How well does a botanical garden collection of a rare palm capture genetic variation in a wild population. Biological Conservation, 14(5), 1110-1117. 
Neil, P.E. (1990). Growing sandalwood in Nepal potential silvicultural methods and research priorities. Proceeding of the symposium on sandalwood in the pacific. Hawaii, April, 9-11, 1990. Berkeley: USDA Forest Service.

Raharjo, S.A.S. (2013). Studi komparasi peraturan daerah cendana di Provinsi NTT. Jurnal Penelitian Kebutanan Wallacea, 2(1), 65-78.

Seng, O.D. (1990). Berat jenis dari jenis-jenis kayu indonesia dan pengertian beratnya kayu untuk. keperluan praktek. (Soewarsono, P.H., Trans.). Bogor: Pusat Penelitian dan Pengembangan Hasil Hutan.

Sumanto, S.E., Sutrisno, E., \& Kurniawan, H. (2011). Analisis kebijakan dan strategi pengembangan kehutanan dalam pengemangan cendana di Nusa Tenggara Timur. Jurnal Analisis Kebijakan Kebutanan, 8(3), 189-209.

Sumardi, Kurniawan, H., \& Misto. (2014). Upaya konservasi dan pelestarian cendana: sebuah kajian. Proseding Seminar Hasil Litbang Peran IPTEK Hasil Hutan Bukan Kayu untuk Kesejabteraan Masyarakat Nusa Tenggara Timur. Kupang, 16 Oktober 2012. Bogor: Pusat
Penelitian dan Pengembangan Konservasi dan Rehabilitasi.

Susiarti, S. (2005). Jenis-jenis pengganti tanaman pinang dan gambir dalam budaya menginang masyarakat di kawasan Taman Nasional Wasur Merauke Papua. Jurnal Biodiversitas, 6(3), 217-219.

Umroni, A., Siswadi, \& Rianawati, H. (2012). Teknik konservasi domestikasi jenis kayu papi (Exocarpus latifolia R.Br) di Pulau Timor. (Laporan Hasil Penelitian). Kupang: Balai Penelitian Kehutanan Kupang.

Umroni, A., Siswadi, \& Rianawati, H. (2013). Teknik konservasi domestikasi jenis kayu papi (Exocarpus latifolia, R.Br) di Pulau Sumba. (Laporan Hasil Penelitian). Kupang: Balai Penelitian Kehutanan Kupang.

Oyen, L.P.A. \& Huan Dun, Nguyen (eds.). (1999). Essential-oil plants. In Plant resource of South East Asia No. 19. Leiden: Backhuys Publiser.

Wawo, A.H. (2008). Studi perkecambahan biji dan pola pertumbuhan semai cendana (Santalum album L.) dari beberapa pohon induk di Kabupaten Belu, NTT. Biodiversitas, 9(2), 177-122. 